\title{
ANAESTHETIC MANAGEMENT OF A CASE OF CONGENITAL LOBAR EMPHYSEMA IN A NEONATE: A CASE REPORT
}

Yerramsetti Atchyutha Ramaiah ${ }^{1}$, B. Sowbagya Lakshmi², Athaluri Vishnuvardhan ${ }^{3}$, Sirisha Vanapalli ${ }^{4}$

\section{HOW TO CITE THIS ARTICLE:}

Yerramsetti Atchyutha Ramaiah, B. Sowbagya Lakshmi, Athaluri Vishnuvardhan, Sirisha Vanapalli. "Anesthetic Management of a Case of Congenital Lobar Emphysema in a Neonate: A Case Report". Journal of Evolution of Medical and Dental Sciences 2014; Vol. 3, Issue 58, November 3; Page: 13203-13208,

DOI: $10.14260 /$ jemds/2014/3757

ABSTRACT: Congenital lobar emphysema (CLE) is a congenital anomaly of the lower respiratory tract characterized by over inflation of alveoli of the one or more lobes of the lung. CLE is potentially reversible, though possibly life threatening cause of respiratory distress in the neonate. We are presenting a 2 week old baby who presented with sudden onset of respiratory distress related to CLE affecting the upper lobe of left lung. Lobectomy was performed under general anesthesia with one lung ventilation. The anesthetic challenges and management of this case are discussed here.

KEYWORDS: Congenital lobar emphysema, lobectomy, Neonate.

INTRODUCTION: CLE is a developmental anomaly of the lower respiratory tract characterized by hyperinflation of one or more lobes of the lung.1, 2 CLE may be diagnosed during prenatal ultrasound (fluid filled distended lobe), but most commonly is detected in neonates when progressive distention causes symptoms from compression of the remaining ipsilateral as well as the contralateral lung, mediastinal shift and tracheo-esophageal compression. If less severe cases, CLE may not present until later infancy or childhood. We discuss the anesthetic management of 2 weeks old neonate requiring Left upper lobectomy who presented with respiratory distress due to CLE affecting Left lung.

CASE REPORT: A 2 week old female term infant weighing $4 \mathrm{~kg}$ presented to emergency ward with a history of chest in drawing, rapid respiratory rate, for the last 7 days. She was delivered by caesarian section, was breastfed and suffered no other medical problem until the presenting complaint. On examination the baby was pale and oxygen saturation was $92 \%$ on Oxygen hood and was in respiratory distress with inter costal retraction and respiratory rate of $64-66 / \mathrm{min}$. On auscultation, air entry was decreased in left lung.

Heart rate was 144/min. Chest radiograph demonstrated hyper inflated left upper lobe, triangular shaped compressed lower lobe, flattening of left hemi diaphragm and marked mediastinal shift to the right. ABG revealed respiratory acidosis with pH7.2, pco2 55mm Hg, po2 of $101 \mathrm{~mm} \mathrm{Hg}$, and base excess of 13. A clinical diagnosis of CLE was made and treatment started in NICU with IV antibiotics, bronchodilators, nebulisation, and chest physiotherapy. Fluid resuscitation was commenced with $16 \mathrm{ml} / \mathrm{kg}$ Dextrose normal saline, that restored capillary return to normal but tachypnea remained.

Baby was nursed in left lateral position with supplemental oxygen via oxygen hood at 10lit/min oxygen. Computed tomography scan of chest confirmed the diagnosis of CLE left upper lobe with gross mediastinal shift. Left upper lobectomy was planned under general anesthesia. We have premedicated the child with $0.01 \mathrm{mg} / \mathrm{kg}$ inj. Atropine IV and inj. Ketamine $5 \mathrm{mg} / \mathrm{kg}$ IM.30minutes before the child is shifted to Operation Theater. 
In the Operation theatre, all the standard monitors like Pulse oximetry, ECG, NIBP, Capnography and Temperature probe were connected. IV line secured with 24G IV cannula. After Preoxygenation for 3minutes with $100 \%$ oxygen, baby was induced with Sevoflurane $8 \%$ with oxygen for one minute and intubated after achieving adequate depth of anesthesia with $3 \mathrm{~mm}$ un cuffed oral ET tube. The tube was passed further down into right main bronchus and fixed at 12 mark at the angle of the mouth to ventilate the right lung preferentially.

Right sided endo bronchial tube position was confirmed by auscultation. We connected the endotracheal tube to Jackson Rees modification of Ayer's T-piece circuit, Anesthesia was maintained with $02+$ Sevoflurane $1 \%+$ inj. atracurium $0.5 \mathrm{mg} / \mathrm{kg}$ iv and inj. fentanyl $1 \mu \mathrm{g} / \mathrm{kg}$ iv with intermittent positive pressure ventilation. Patient was placed in right lateral decubitus position, supported by axillary rolls with head supported by a donut. During initial period of left thoracotomy position, an oxygen concentration of $100 \%$ was required to maintain Spo2 of $99 \%$.

After the left upper lobe was isolated \& clamped, bronchopulmonary artery \& vein were ligated \& divided; oxygen saturation stabilized at $97 \%$ on $40 \%$ oxygen, $\mathrm{N}_{2} \mathrm{O}$ was then started. Intermittent suctioning of tracheal tube was done intra operatively. After the removal of emphysematous left upper lobe, the tracheal tube was withdrawn up to $9^{\text {th }}$ mark and ventilation of both lungs were established. IV Fluid was maintained with Dextrose normal saline $80 \mathrm{ml}$ in the 1 sthour, a left chest drain was left in situ.

For post-operative analgesia, local infiltration along the skin incision and intercostal nerve block before closure of thoracotomy was given with $5 \mathrm{ml}$ of $0.25 \%$ Bupivacaine thereafter analgesia was maintained with Per Rectal suppositories of paracetamol $40 \mathrm{mg} / \mathrm{kg}$. The baby was electively ventilated in NICU for 24 hours and weaned off successfully and extubated on the second day. Postoperatively, the chest radiograph was repeated in the evening of the surgery and revealed complete correction of mediastinal shift and marked expansion of left lung. Post-operative course is uneventful and patient discharged on seventh day.

DISCUSSION: CLE is a rare congenital anomaly characterized by over distention of the lung. It may be associated with anomalies of the bronchial cartilage (reduced or absent bronchial cartilage resulting in intrinsic bronchial narrowing and bronchomalacia) or external bronchial compression from various causes resulting in air trapping. CLE can be hypo alveolar (reduced number of alveoli) or poly alveolar (increased number of alveoli). Typically only one lobe is involved (left upper lobe: 41\%, right middle lobe: $34 \%$, right upper lobe: $21 \%)^{3}$

CLE may be diagnosed during prenatal ultrasound (fluid filled distended lobe), but most commonly is detected in neonates when progressive distention causes symptoms from compression of the remaining ipsilateral as well as the contralateral lung, mediastinal shift and tracheo-esophageal compression. ${ }^{4}$ If less severe, CLE may not present until later infancy or childhood. Associated anomalies such as congenital heart disease are present in $10 \%$ of patients with CLE.

The age of onset of symptoms ranges from a few days after birth to 6 months. ${ }^{5}$

Most patients develop symptoms in neonatal period and male to female ratio is $3: 1 .^{6}$

As in this child, respiratory distress is the commonest mode of presentation. There is dyspnea, wheezing, grunting respiration, tachypnea, and sometimes progressive cyanosis. Similar symptoms may occur in bronchopneumonia, cyanotic congenital heart disease, and severe congenital anomalies of the lung.7,8 
The basic investigation in CLE is chest radiograph with which diagnosis can be made and is readily available. CT scan confirms the diagnosis. Bronchoscopy and Scintigraphy are other investigative procedures. ${ }^{9}$ Thoracotomy and complete lobectomy are treatment options usually required for CLE. 10 The physiological considerations for anaesthetizing these patients include ventilation and perfusion impairment of the lung in lateral decubitus position.

As these babies have low baseline saturations, induction of anesthesia is very critical, as crying, struggling can cause increase in the amount of trapped gas and also positive pressure ventilation to assist the ventilation also increases the emphysema. So, the target should be to achieve smooth inhalational induction. In our patient, we induced the baby with sevoflurane in oxygen without assisted ventilation. An alternative induction approach, especially for the unstable infant is sedation with intravenous Ketamine. ${ }^{11}$ After the intra thoracic pressure has been released, general anesthesia can proceed with any other appropriate technique.

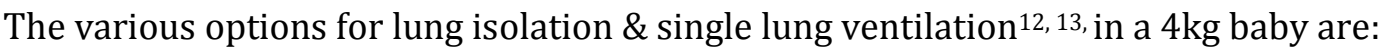

1. Double lumen tube - Marraro double lumen tube for neonates and infants

2. Bronchial blocker.

a) Fogarty catheter $(3,4,5 \mathrm{~F})$.

b) Arndt endobronchial blocker (smallest 5F).

3. Mainstem bronchus intubation with endo tracheal tube.

DLTS freely and commercially not available, single lumen tubes are used for tracheal intubation commonly. Alternatively selective mainstem bronchus intubation can be done as we have done in our case. In small infants, lung isolation is technically difficult and not commonly practiced. ${ }^{14}$

The physiologic considerations of one lung ventilation in a neonate compared to an adult are:

1. Higher oxygen consumption.

2. Immature alveoli.

3. Increased chest wall compliance impedes the oxygenation of the healthy dependent lung unlike adults.

Airway management in a patient with CLE is a challenging task. The challenges are both respiratory and cardiovascular. In this case, it is necessary to avoid IPPV until the diseased lung is isolated, because further inflation of the diseased lung causes compromise of the normal lung. ${ }^{15-18}$

Various other alternatives include placement of a bronchial blocker under fluoroscopic guidance, High frequency jet ventilation ${ }^{19}$ has been used successfully in the patients with CLE, as low airway pressures are suitable for the neonates. $\mathrm{ECMO}^{20}$ has been used to maintain oxygenation in children with persisting pulmonary acquired interstitial emphysema.

In our patient, ventilation was started once the right bronchial intubation was successful.

In summary, a 2-week-old baby presented with sudden onset of respiratory distress related to CLE affecting the left upper lobe. Upper Lobectomy was performed after induction with Sevoflurane in oxygen, with the child breathing spontaneously. Intermittent positive pressure ventilation with oxygen and air was not commenced until right endo bronchial intubation was achieved. Left upper lobectomy was performed uneventfully and the child was discharged from the hospital on the $7^{\text {th }}$ postoperative day. 
CONCLUSION: We conclude that the successful outcome of a patient with congenital lobar emphysema depends upon the thorough understanding of pathophysiology of one lung ventilation, methods of lung isolation, maintaining perioperative hemodynamic stability and good postoperative ventilation with adequate postoperative analgesia.

\section{REFERENCES:}

1. Kravitz RM. Congenital malformations of the lung. Pediatr Clin North Am 1994; 41: 453-72.

2. Stanton M, Davenport M. Management of congenital lung lesions. Early Hum Dev 2006; 82: 28995.

3. Calvert JK, et al. Outcome of antenatally suspected congenital cystic adenomatoid malformation of the lung: 10 years' experience 1991-2001. Arch Dis Child Fetal Neonatal Ed 2006; 91: F26-28.

4. Shanmugam G, MacArthur K, and Pollock JC. Congenital lung malformations--antenatal and postnatal evaluation and management. Eur J Cardiothorac Surg 2005; 27: 45-52.

5. Bappal B, Ghani SA, Chaudhary R, Sajvani MJ. Congenital lobar emphysema: a review of 10 cases. Indian J Pediatr 1996; 63: 801-8.

6. Cay A, Sarihan H. Congenital malformations of the lung. J Cardiovasc Sur (Torino) 2000; 41: 507-10.

7. Mikhailova V. Congenital lobar emphysema in childhood. Khirurgiia (Sofia) 1996; 49: 8-12.

8. Takeda S, Miyoshi S, Inoue M, Omori K, Okumura M, Yoon HE et al. Clinical spectrum of congenital cystic disease of the lung in children. Eur J Cardiothorac Surg 1999; 15: 11-7.

9. Ulku R, Onat S, Ozçelık C. Congenital lobar emphysema: Differential diagnosis and therapeutic approach. Pediatrics International (2008) 50, 658-661.

10. Mikhailova V. Congenital lobar emphysema in childhood. Khirurgiia (Sofia) 1996; 49: 8-12.

11. Cote CJ. The anaesthetic management of congenital lobar emphysema. Anaesthesiology 1978; 49: 296-8.

12. Pawar DK, Marraro GA. One lung ventilation in infants and children: experience with Marraro double lumen tube. Pediatr Anesth 2005; 15: 204-208.

13. Marraro G. Selective endobronchial intubation in paediatrics: the Marraro Paediatric Bilumen Tube. Paediatr Anaesth 1994; 4: 255-258.

14. Hammer GB, Fitzmaurice BG, Brodsky JB. Methods for single lung ventilation in paediatric patients. Anaesth Analg 1999; 89: 1426-9.

15. Al-Salem AH, Adu-Gyamfi Y, Grant CS. Congenital lobar emphysema. Can J Anaesth 1990; 37: 377-9.

16. Lt Col DK Sreevastava, Maj S Kiran. Anaesthetic Management of Congenital Lobar Emphysema: A Report of Two Cases. Medical Journal Armed Forces India, 2005; 61: 79-81.

17. Chandran-Mahaldar D, Kumar S, Balamurugan K, Raghuram AR, Krishnan R, Kannan. Congenital lobar emphysema. Indian J Anaesth 2009; 53: 482-5.

18. Tempe DK, Virmani S, Javetkar S, Banerjee A, Puri SK, Datt V. Congenital lobar emphysema: pitfalls and management. Ann Card Anaesth 2010: 13: 53-8.

19. Goto H, Boozalis ST, Benson KT, Arakawa K. High frequency jet ventilation for resection of congenital lobar emphysema. Anaesth Analg 1987; 66: 684-6.

20. Trento A, Thompson A, Siewers RD, Orr RA, Kochanek P,Fuhrman B, et al. Extracorporeal membrane oxygenation in children. New trends. J Thoracic Cardiovasc Surg 1988; 96: 542-7. 


\section{CASE REPORT}

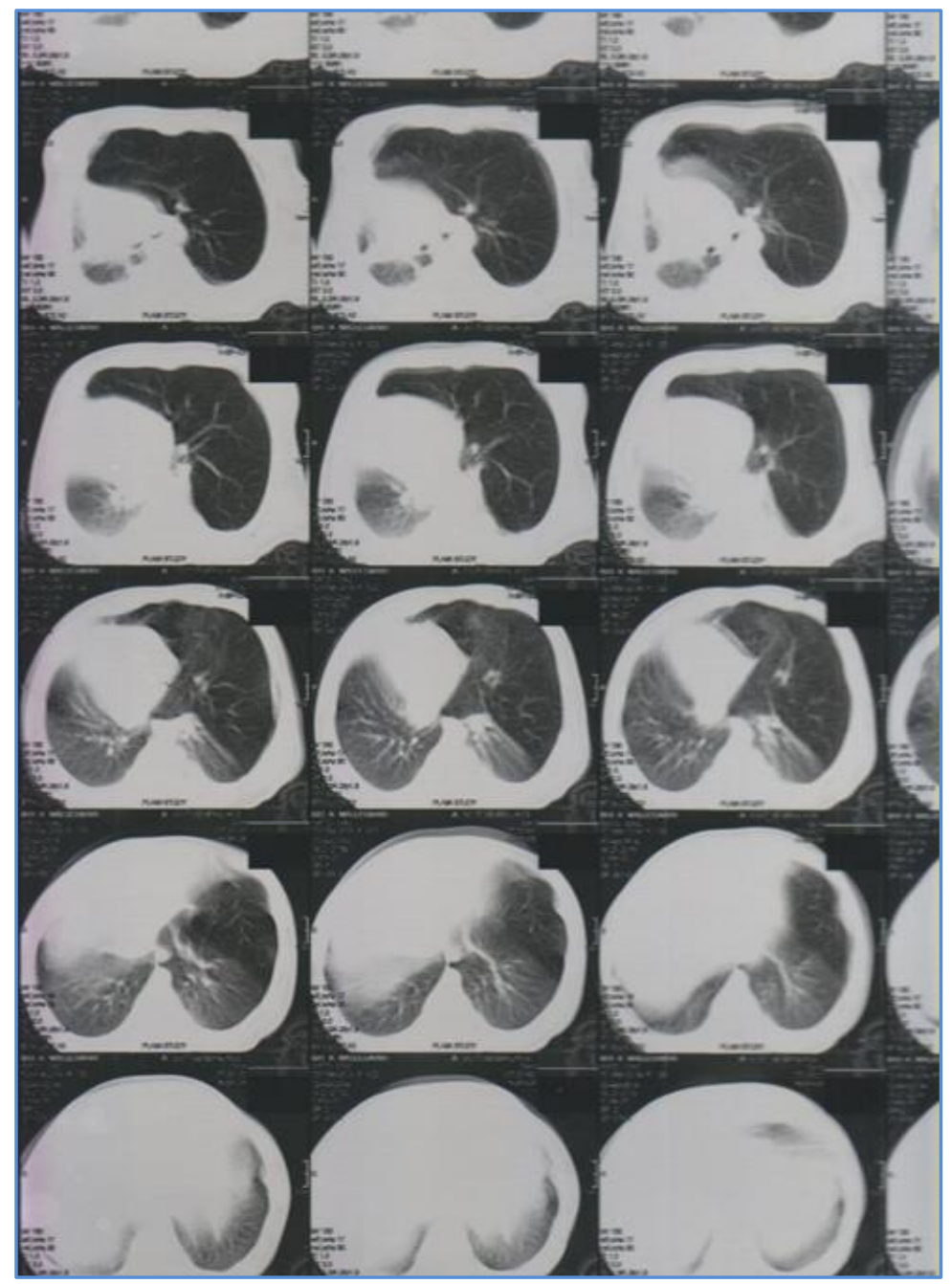

Fig. 1: CT scan showing hyper inflated left upper lobe, triangular shaped compressed lower lobe, flattening of left hemi diaphragm and marked mediastinal shift to the right

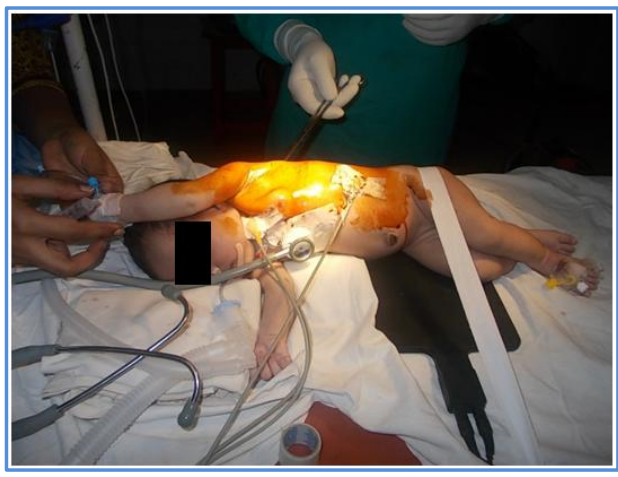

Fig. 2: Intubated neonate kept in lateral decubitus position

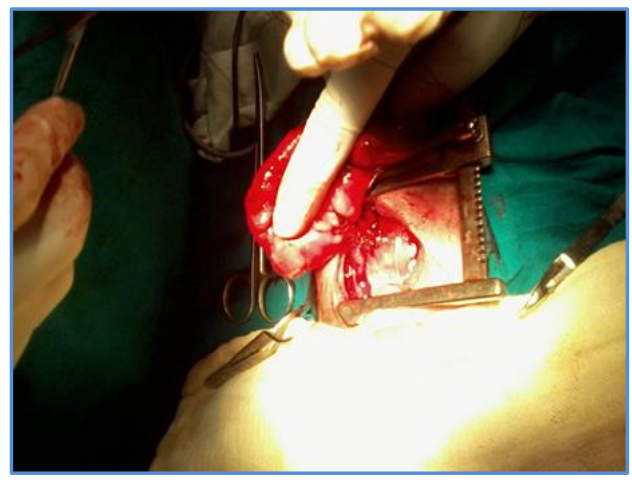

Fig. 3: Left lung-uppe rlobe isolated during surgery 


\section{CASE REPORT}

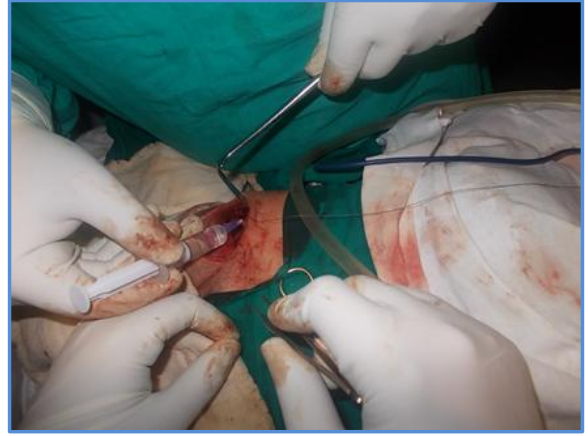

Fig. 4: Intercostal nerve block for post-operative analgesia

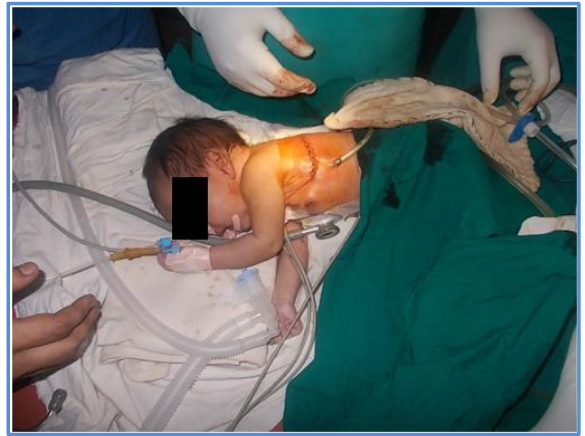

Fig. 5: After the end of surgery intercostal tube in place

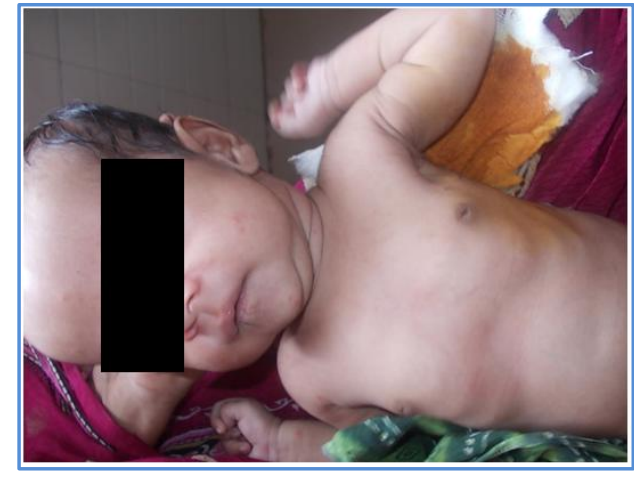

Fig. 6: Neonate before discharge

\section{AUTHORS:}

1. Yerramsetti Atchyutha Ramaiah

2. B. Sowbagya Lakshmi

3. Athaluri Vishnuvardhan

4. Sirisha Vanapalli

\section{PARTICULARS OF CONTRIBUTORS:}

1. Assistant Professor, Department of Anaesthesiology, Rangaraya Medical College.

2. Professor \& HOD, Department of Anaesthesiology, Rangaraya Medical College.

3. Associate Professor, Department of Anaesthesiology, Rangaraya Medical College.
4. Post Graduate, Department of Anaesthesiology, Rangaraya Medical College.

\section{NAME ADDRESS EMAIL ID OF THE CORRESPONDING AUTHOR:}

Dr. Yerramsetti Atchyutha Ramaiah, Assistant Professor,

Department of Anesthesiology, \#65-10-2, Mantri Pragadavari Veedhi, Karanamgari Junction,

Kakinada-533004.

Email: yerramsetti.atchyuth@gmail.com

Date of Submission: 25/10/2014.

Date of Peer Review: 27/10/2014.

Date of Acceptance: 31/10/2014.

Date of Publishing: 01/11/2014. 